\title{
SocioCultural and Religious Impacts Upon Covid-I 9 Pandemic Physical Distancing Public Practices
}

\author{
Mudhar Al Adawi' \\ Hasina Al Harthi ${ }^{2}$ \\ Samiha Al Habsi ${ }^{1}$ \\ Khalid Al Busaidi $\mathbb{D D}^{2}$ \\ Issa Al Salmi $\mathbb{D}^{3,4}$
}

'Department of Nursing, Royal Hospital, Muscat, Oman; ${ }^{2}$ Department of Training \& Studies, Royal Hospital, Muscat, Oman; ${ }^{3}$ Medicine Department, Royal Hospital, Muscat, Oman; ${ }^{4}$ Internal Medicine, Oman Medical Specialty Board, Muscat, Oman
Correspondence: Issa Al Salmi Oman Medical Specialty Board and The Royal Hospital, 23 July Street, P O Box I33I, Muscat, III, Oman Tel +96892709000

Fax +96824599966

Email isa@ausdoctors.net
Introduction: COVID-19 is the first pandemic event that has happened in Oman which requires all residents and nationals to practice quarantine and physical distancing.

Methods: This cross-sectional study targeted the population of Oman and was carried out during the first wave of the COVID-19 pandemic from 11th August 2020 to 7th September 2020. This study utilized the online survey most appropriately designed for the population. The survey was distributed to the public through social media and text messages. The survey was translated into the four main spoken languages in Oman, which are Arabic, English, Swahili, and Hindi.

Results: A total of 943 residents responded to the online survey. The majority of respondents reported that they are ready/ready to a great extent to practice physical distancing $(61.9 \%)$ during the pandemic compared to $34.9 \%$ not sure/ready to some extent and $3.2 \%$ not ready at all for physical distancing. It was found that financial factors, religious and culturalnorms had the strongest negative-impact to maintain physical distancing. While level of responsibility, governmental legislations, and fear of getting or transmitting the infection had the strongest positive impact to maintain physical distancing. Males reported a greater financial and religious negative impact of physical distancing with p-values of 0.002 and 0.001 , respectively. Females reported a greater positive impact of family and friend's support and legislation with p-values of 0.046 and 0.008 , respectively.

Conclusion: Religious practices mainly negatively affected the male gender during this pandemic which hindered the adherence to physical distancing. This could be due to culture and norms that derive from human behavior within communities and may affect the safety measures during an outbreak or pandemic. Hence, even with availability of vaccinations, campaigns on public health and the utilization of faith leaders should be the national practice to continue emphasizing compassionate attitudes towards physical distancing.

Keywords: COVID-19, quarantine, physical distancing, culture, religious practices

\section{Plain Language Summary}

This cross-sectional survey included close and open-ended questions including details regarding the knowledge, belief and the impact of physical distancing, and readiness to change social life and comply with the physical distancing requirements.

The majority of respondees reported that they are ready/ready to a great extent to practice physical distancing (61.9\%) compared to $34.9 \%$ reported that they are not sure/ready to some extent and only $3.2 \%$ were not ready at all to practice physical distancing.

Financial factors, religious and cultural-norms had the strongest negative impact. While level of responsibility, governmental legislations, and fear of getting or transmitting the 
infection had the strongest positive impact to practice physical distancing among all the respondents.

Males reported a greater financial and religious negative impact with p-values of 0.002 and 0.001 , respectively. Females reported a greater positive impact of family and friend's support and legislation with p-values of 0.046 and 0.008 , respectively.

This study highlighted the readiness of a population to practice physical distancing, their knowledge of physical distancing, and the impact of physical distancing on different life factors.

Culture and norms derive the human behavior within communities and may affect the safety measures during an outbreak or pandemic. Hence, even with the availability of vaccinations, campaigns on public health should be the national practice to continue emphasizing compassionate attitudes towards physical distancing.

\section{Introduction}

Coronaviruses (CoVs) are a group of highly diverse, enveloped single-stranded RNA viruses. Over the last 20 years, the world has faced two novel CoVs, severe acute respiratory syndrome $\mathrm{CoV}$ (SARS-CoV) and Middle East respiratory syndrome $\mathrm{CoV}$ (MERS-CoV), which cause severe human diseases. ${ }^{1}$ Coronaviruses cause severe respiratory, enteric, hepatic, and neurological system diseases among humans and animals. ${ }^{2}$ The severe acute respiratory syndrome coronavirus 2 (SARS-CoV-2) that was discovered in Wuhan, China by the end of 2019 and causes the Coronavirus disease 2019 (COVID-19) is a newly emerging zoonotic coronavirus. ${ }^{3}$ Further analysis revealed that SARS-Cov-2 was found in frozen food packaging and cold chain products that were supplied from China.

Like other countries, the Sultanate of Oman was affected by COVID-19 in early 2020 as travelers returned to their home country. ${ }^{4,5}$ Therefore, cases started rising as time progressed which led to the closure of cities and house restriction all around the country. The fundamental problem associated with the treatment of diagnosed/suspected people with COVID-19 is the introduction of appropriate precautions against transmission of infection to the community and among healthcare providers. Moreover, since the start of this pandemic there have been many unfortunate complications and deaths among infected individuals. To date, there have been 182,229,823 confirmed cases and 3,946,481 deaths around the world, while in Oman there has been a total of 264,302 confirmed cases and 3013 deaths from
COVID-19 (worldmeter, 2021 https://www.worldometers. info/coronavirus/).

COVID-19 spreads by droplets from an infected person's mouth or nose when he/she coughs, sneezes, or talks, and are launched into the air and eventually land in the mouths or noses or inhaled into the lungs of people nearby. ${ }^{6}$ Recently, studies indicated that people who are infected but do not exhibit any symptoms are likely to spread COVID-19. ${ }^{7,8}$ Therefore, it is important to maintain precautionary measures like staying at least 1 to 2 meters away from each other even if people do not have any symptoms. Keeping this safe distance between people who are not from the same household is known as "physical distancing". It is particularly very important for those who are at a higher risk for severe illness from COVID-19. However, physical distancing should not be practiced solely but in combination with other preventive measures like wearing masks, avoiding touching your face with unwashed hands, and frequently washing your hands with soap and water for at least 20 seconds to reduce the spread of COVID-19. ${ }^{9}$

As this is the first pandemic event that has happened in the country which requires all residents and nationals to practice quarantine and physical distancing, there could be certain issues related to cultural values and community that affect the practice of these measures. Therefore, this study is going to explore the population's knowledge, practices and beliefs about physical distancing during a pandemic event. We hypothesize that there are certain values within the community that affect the population's practice and adherence to physical distancing in a pandemic event.

\section{Methods and Materials}

\section{Study Population and Design}

This cross-sectional study was approved by the Scientific Research Committee at the Royal Hospital, $\mathrm{MOH}$, with approval number SRC\#65/2020. Participants consent was integrated along with the online questionnaire and all data were maintained anonymously with the primary researcher. The study was approved by the Scientific Research Committee and the study was performed in accordance with the ethical standards as laid down in the 1964 Declaration of Helsinki and its later amendments on ethical standards (https://mohcsr.gov.om/my-researches/).

An online questionnaire (Figure S1) was used to collect the data and was carried out during the first wave of the 
COVID-19 pandemic from 11th August 2020 to 7th September 2020. This study sampling is convenient as it targeted nationals and residents of Oman who had access either to Whatsapp, social media, or internet. This study included all nationals and residents in Oman who can read any of the four main languages (Arabic, English, Swahili, Hindi) and have internet access to fill in the survey. The required sample size was calculated to be 385 based on a margin of error of $5 \%$, confidence interval of $95 \%$, a population of 4 million, and the response distribution being $50 \%$ and power of $80 \%$. This calculation was done through Raosoft for a sample size calculation.

\section{Questionnaire}

Researchers developed the questionnaire based on the aim and hypothesis of the study, which was to underline the population practices and beliefs about physical distancing during outbreaks and pandemics. We hypothesized that there are certain values that affect the practice of physical distancing during the COVID 19 pandemic. All questions were extracted from literature related to pandemic physical distancing then modified according to the study objectives and hypothesis.

The survey included close- and open-ended questions. In the first section of the questionnaire, participants were asked to specify demographical details including age, marital status, living with high-risk groups, health status, job status and income in order to correlate the practice of physical distancing along with the demographical data. The second section of the questionnaire included details regarding their knowledge, belief and the impact of physical distancing, and readiness to change social life and comply with the physical distancing. In the open-ended part of the questionnaire, participants could express their experience of physical distancing, compliance challenges and their recommendations.

After initial design of the tool, the research team reviewed the content along with the objectives and hypothesis. For content validation, the researchers validated the tool with an expert. The instrument of this study was reviewed by three researchers, and the questionnaire was developed in English by the researcher then it was translated into three other languages (Arabic, Swahili (which is an African language), and Hindi (which is a native language of the India subcontinent)). The tool was tested in all four languages for maximum validation.

The online questionnaire was distributed to different hospital administrations, community charity associations, and stakeholders from various governmental and private sectors, and educational stakeholders through various social media apps, such as WhatsApp and Twitter accounts. In data collection, the Triangulation method was used to recruit more participants (random sampling and snowball sampling).

Descriptive analysis that includes frequencies and percentages was used to analyze the results. Analytical tests used are the Chi-square test and a p-value of 0.05 was used to compare demographic data such as gender, age, citizenship, place of living, and educational background with beliefs and practices of physical distancing.

\section{Results}

A total of 943 respondents were recruited to this study. The majority of them reported that they are ready/ready to a great extent to practice physical distancing (61.9\%), compared to $34.9 \%$ reporting that they are not sure/ready to some extent and only $3.2 \%$ were not ready at all to practice physical distancing, as shown in Table 1.

Younger age group, female, Omani citizen, living outside Muscat and with high education were the main characteristics of the non-ready group. While the majority of those from self-income or working in private sector and with special medical condition or living with someone with special medical condition reported better readiness, as shown in Table 1.

Financial factors, religious and cultural norms had the strongest negative impact. While level of responsibility, governmental legislations, and fear of getting or transmitting the infection had the strongest positive impact to practice physical distancing among all the respondents, as shown in Table 2 and Figure 1.

Males reported a greater financial and religious negative impact with p-values of 0.002 and 0.001 , respectively. Females reported a greater positive impact of family and friend's support and legislation with p-values of 0.046 and 0.008 , respectively.

Respondents in the age group 24-45 reported greater negative impacts of financeand the fear of transmitting the infection with p-values of 0.002 and 0.015 , respectively. While the older age group reported a more positive impact of family and friend's support (p-value 0.067).

Figure 2 shows that the majority of those reported to be not ready at all for physical distancing reported that they had an idea about the meaning of physical distancing (26/ 30 ) and the remaining reported that they had some information. Less than $1 \%(n=6)$ respondents reported that they had no idea about the meaning of physical distancing, 


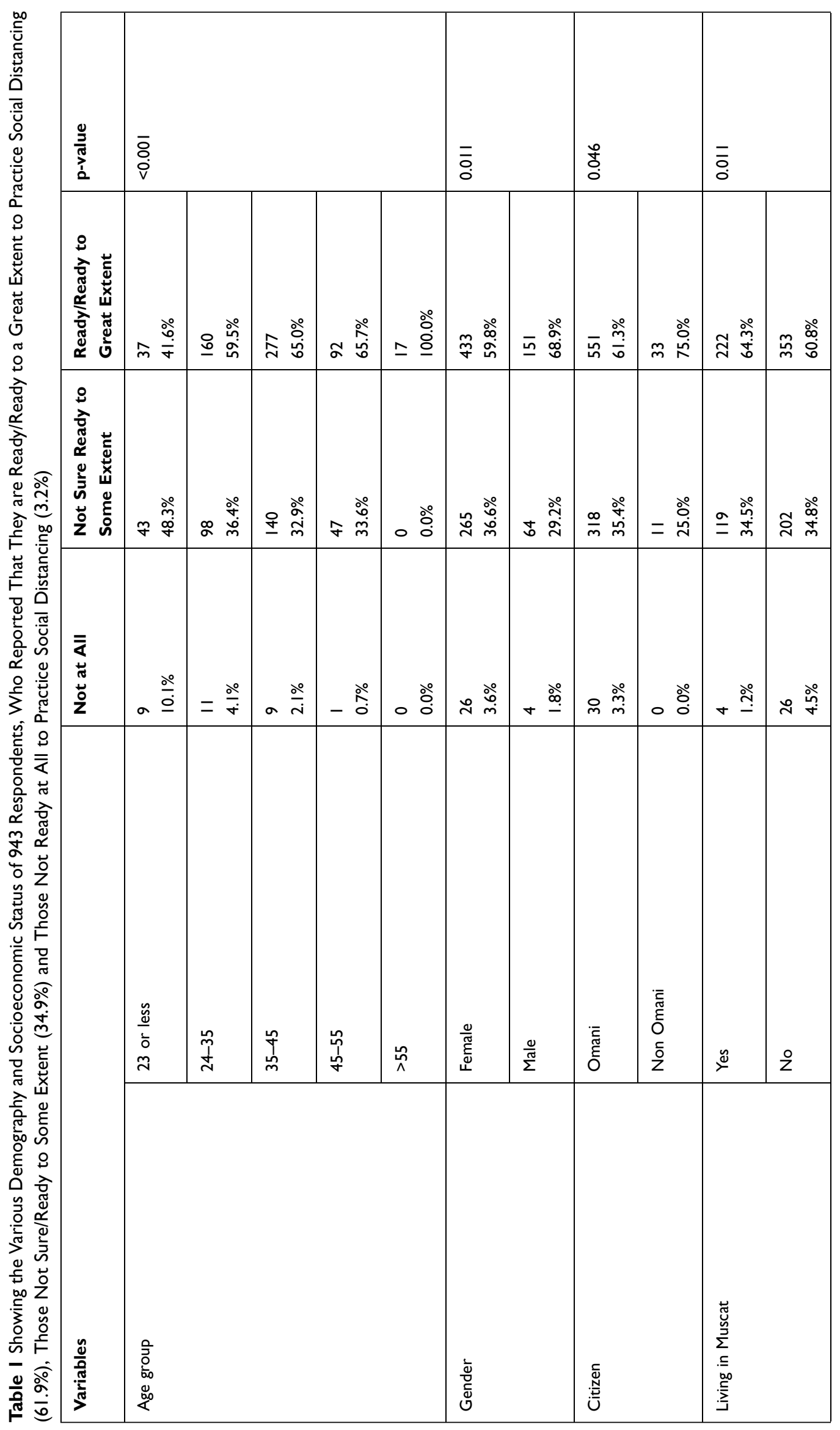




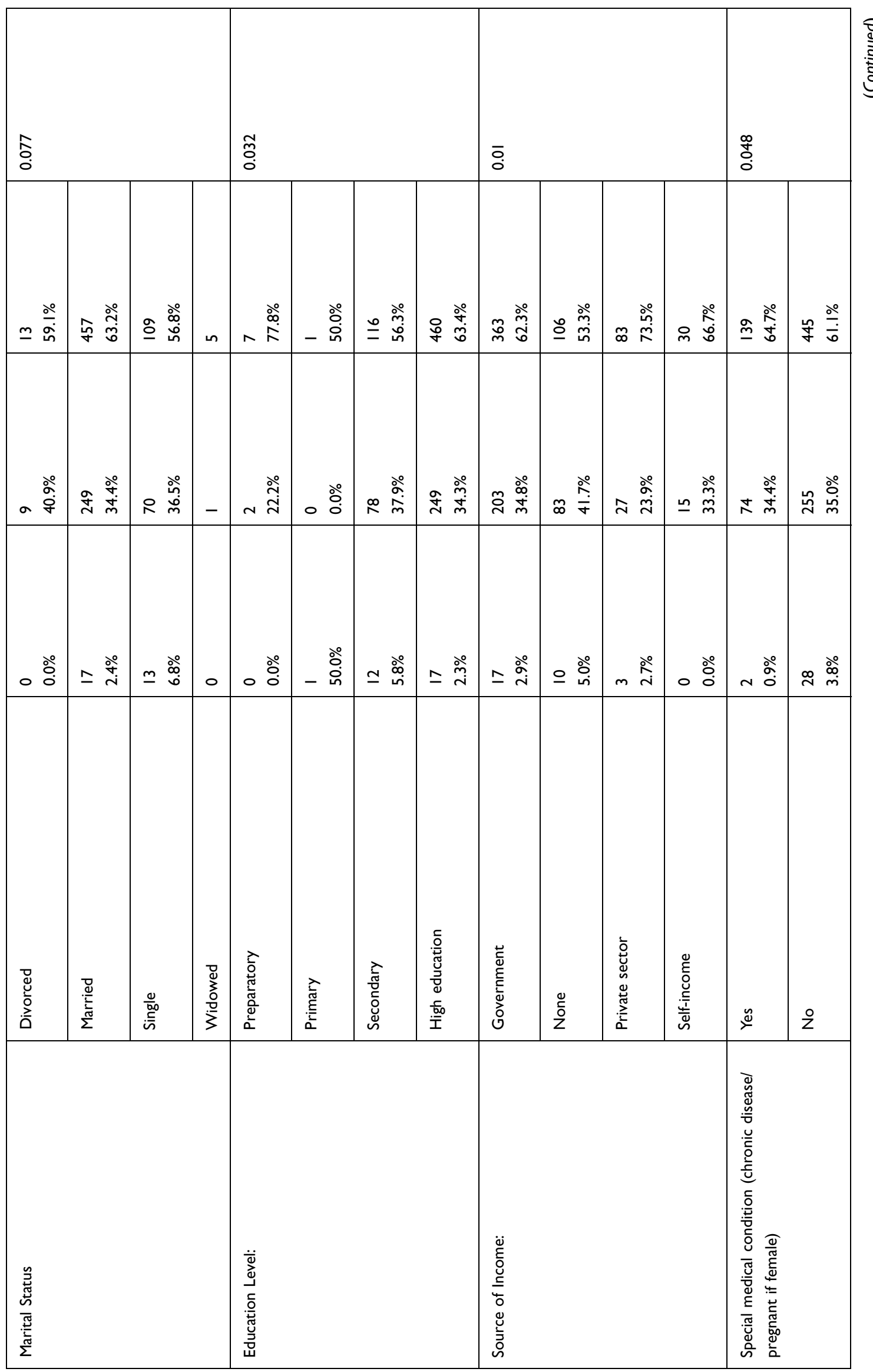




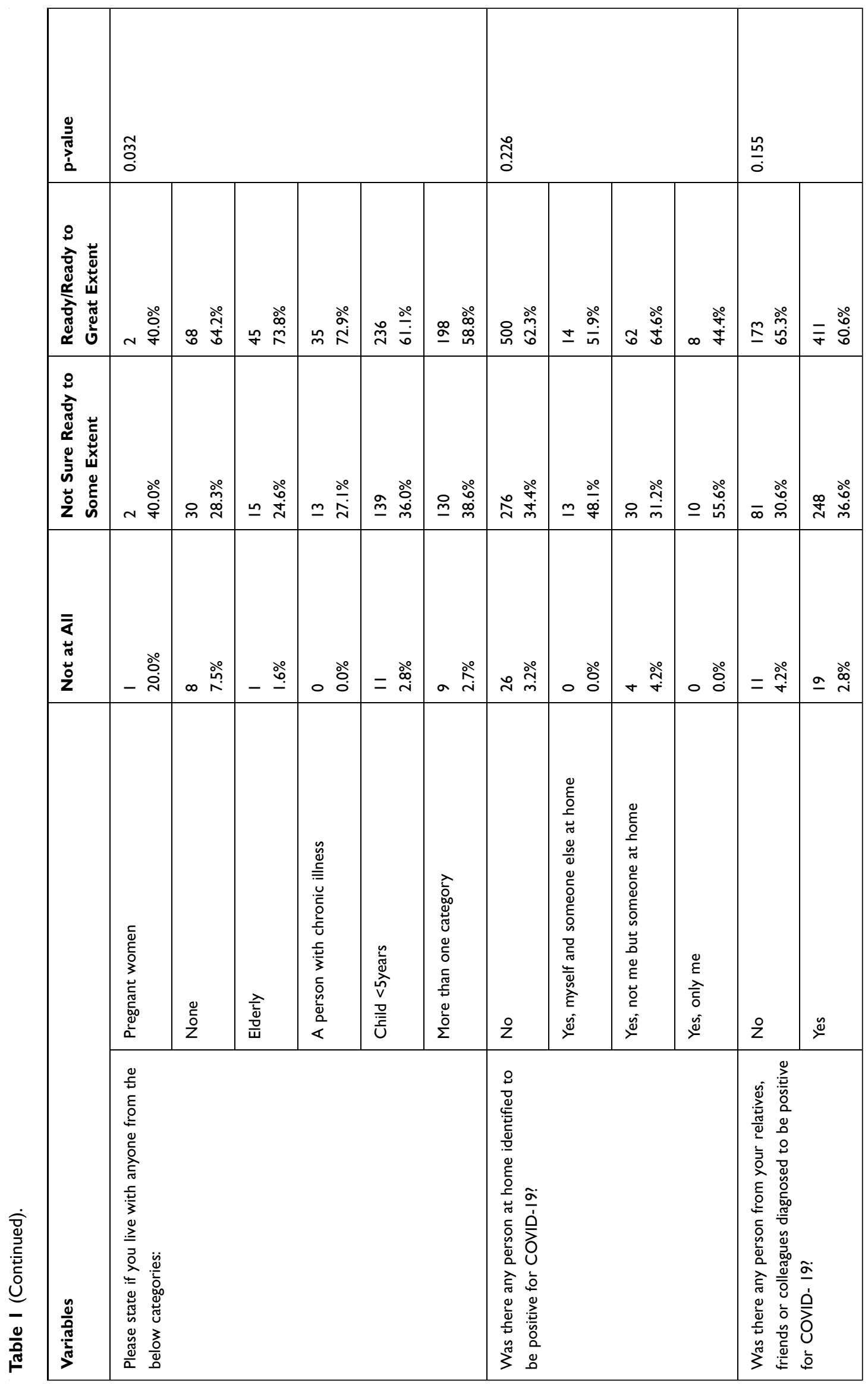


Table 2 Reported Factors Impacting Social Distancing

\begin{tabular}{|c|c|c|c|c|c|c|}
\hline Factor & $\begin{array}{l}\text { Strong Negative } \\
\text { Impact }\end{array}$ & $\begin{array}{l}\text { Negative } \\
\text { Impact }\end{array}$ & $\begin{array}{l}\text { No } \\
\text { Impact }\end{array}$ & $\begin{array}{l}\text { Positive } \\
\text { Impact }\end{array}$ & $\begin{array}{l}\text { Strong Positive } \\
\text { Impact }\end{array}$ & Total \\
\hline \multicolumn{7}{|l|}{ IFI: Financial status } \\
\hline Not ready at all & $\begin{array}{l}12 \\
4.9 \%\end{array}$ & $\begin{array}{l}4 \\
2.4 \%\end{array}$ & $\begin{array}{l}11 \\
3.9 \%\end{array}$ & $\begin{array}{l}3 \\
1.8 \%\end{array}$ & $\begin{array}{l}0 \\
0.0 \%\end{array}$ & $\begin{array}{l}30 \\
3.2 \%\end{array}$ \\
\hline Not sure/ready to some extent & $\begin{array}{l}91 \\
37.1 \%\end{array}$ & $\begin{array}{l}62 \\
37.1 \%\end{array}$ & $\begin{array}{l}93 \\
33.2 \%\end{array}$ & $\begin{array}{l}53 \\
32.5 \%\end{array}$ & $\begin{array}{l}30 \\
34.1 \%\end{array}$ & $\begin{array}{l}329 \\
34.9 \%\end{array}$ \\
\hline Ready /ready to a great extent & $\begin{array}{l}142 \\
58.0 \%\end{array}$ & $\begin{array}{l}101 \\
60.5 \%\end{array}$ & $\begin{array}{l}176 \\
62.9 \%\end{array}$ & $\begin{array}{l}107 \\
65.6 \%\end{array}$ & $\begin{array}{l}58 \\
65.9 \%\end{array}$ & $\begin{array}{l}584 \\
61.9 \%\end{array}$ \\
\hline \multicolumn{7}{|l|}{ IF2: Religious } \\
\hline Not ready at all & $\begin{array}{l}14 \\
5.4 \%\end{array}$ & $\begin{array}{l}5 \\
3.4 \%\end{array}$ & $\begin{array}{l}6 \\
2.6 \%\end{array}$ & $\begin{array}{l}3 \\
2.1 \%\end{array}$ & $\begin{array}{l}2 \\
1.3 \%\end{array}$ & $\begin{array}{l}30 \\
3.2 \%\end{array}$ \\
\hline Not sure/ready to some extent & $\begin{array}{l}97 \\
37.2 \%\end{array}$ & $\begin{array}{l}69 \\
46.3 \%\end{array}$ & $\begin{array}{l}67 \\
28.9 \%\end{array}$ & $\begin{array}{l}40 \\
27.4 \%\end{array}$ & $\begin{array}{l}56 \\
36.1 \%\end{array}$ & $\begin{array}{l}329 \\
34.9 \%\end{array}$ \\
\hline Ready /ready to a great extent & $\begin{array}{l}150 \\
57.5 \%\end{array}$ & $\begin{array}{l}75 \\
50.3 \%\end{array}$ & $\begin{array}{l}159 \\
68.5 \%\end{array}$ & $\begin{array}{l}103 \\
70.5 \%\end{array}$ & $\begin{array}{l}97 \\
62.6 \%\end{array}$ & $\begin{array}{l}584 \\
61.9 \%\end{array}$ \\
\hline \multicolumn{7}{|c|}{ IF3: Culture norms that you get use to } \\
\hline Not ready at all & $\begin{array}{l}15 \\
5.3 \%\end{array}$ & $\begin{array}{l}5 \\
2.0 \%\end{array}$ & $\begin{array}{l}7 \\
3.4 \%\end{array}$ & $\begin{array}{l}2 \\
1.7 \%\end{array}$ & $\begin{array}{l}1 \\
1.1 \%\end{array}$ & $\begin{array}{l}30 \\
3.2 \%\end{array}$ \\
\hline Not sure/ready to some extent & $\begin{array}{l}105 \\
37.2 \%\end{array}$ & $\begin{array}{l}92 \\
37.6 \%\end{array}$ & $\begin{array}{l}70 \\
34.1 \%\end{array}$ & $\begin{array}{l}36 \\
30.5 \%\end{array}$ & $\begin{array}{l}26 \\
28.0 \%\end{array}$ & $\begin{array}{l}329 \\
34.9 \%\end{array}$ \\
\hline Ready /ready to a great extent & $\begin{array}{l}162 \\
57.4 \%\end{array}$ & $\begin{array}{l}148 \\
60.4 \%\end{array}$ & $\begin{array}{l}128 \\
62.4 \%\end{array}$ & $\begin{array}{l}80 \\
67.8 \%\end{array}$ & $\begin{array}{l}66 \\
71.0 \%\end{array}$ & $\begin{array}{l}584 \\
61.9 \%\end{array}$ \\
\hline \multicolumn{7}{|c|}{ IF4: Support from family and friends } \\
\hline Not ready at all & $\begin{array}{l}12 \\
6.9 \%\end{array}$ & $\begin{array}{l}3 \\
1.6 \%\end{array}$ & $\begin{array}{l}8 \\
3.3 \%\end{array}$ & $\begin{array}{l}5 \\
2.6 \%\end{array}$ & $\begin{array}{l}2 \\
1.4 \%\end{array}$ & $\begin{array}{l}30 \\
3.2 \%\end{array}$ \\
\hline Not sure/ready to some extent & $\begin{array}{l}59 \\
33.7 \%\end{array}$ & $\begin{array}{l}80 \\
41.7 \%\end{array}$ & $\begin{array}{l}97 \\
39.9 \%\end{array}$ & $\begin{array}{l}49 \\
25.5 \%\end{array}$ & $\begin{array}{l}44 \\
31.2 \%\end{array}$ & $\begin{array}{l}329 \\
34.9 \%\end{array}$ \\
\hline Ready/ready to a great extent & $\begin{array}{l}104 \\
59.4 \%\end{array}$ & $\begin{array}{l}109 \\
56.8 \%\end{array}$ & $\begin{array}{l}138 \\
56.8 \%\end{array}$ & $\begin{array}{l}138 \\
71.9 \%\end{array}$ & $\begin{array}{l}95 \\
67.4 \%\end{array}$ & $\begin{array}{l}584 \\
61.9 \%\end{array}$ \\
\hline \multicolumn{7}{|l|}{ IF5: Responsibility and awareness } \\
\hline Not ready at all & $\begin{array}{l}10 \\
7.9 \%\end{array}$ & $\begin{array}{l}6 \\
5.1 \%\end{array}$ & $\begin{array}{l}6 \\
3.8 \%\end{array}$ & $\begin{array}{l}5 \\
2.1 \%\end{array}$ & $\begin{array}{l}3 \\
1.0 \%\end{array}$ & $\begin{array}{l}30 \\
3.2 \%\end{array}$ \\
\hline Not sure/ready at some extent & $\begin{array}{l}32 \\
25.4 \%\end{array}$ & $\begin{array}{l}52 \\
44.1 \%\end{array}$ & $\begin{array}{l}71 \\
45.5 \%\end{array}$ & $\begin{array}{l}82 \\
34.6 \%\end{array}$ & $\begin{array}{l}92 \\
30.1 \%\end{array}$ & $\begin{array}{l}329 \\
34.9 \%\end{array}$ \\
\hline Ready/ready to a great extent & $\begin{array}{l}84 \\
66.7 \%\end{array}$ & $\begin{array}{l}60 \\
50.8 \%\end{array}$ & $\begin{array}{l}79 \\
50.6 \%\end{array}$ & $\begin{array}{l}150 \\
63.3 \%\end{array}$ & $\begin{array}{l}211 \\
69.0 \%\end{array}$ & $\begin{array}{l}584 \\
61.9 \%\end{array}$ \\
\hline \multicolumn{7}{|l|}{ IF6: Legislations of the government } \\
\hline Not ready at all & $\begin{array}{l}9 \\
6.9 \%\end{array}$ & $\begin{array}{l}4 \\
3.9 \%\end{array}$ & $\begin{array}{l}7 \\
4.2 \%\end{array}$ & $\begin{array}{l}7 \\
2.5 \%\end{array}$ & $\begin{array}{l}3 \\
1.1 \%\end{array}$ & $\begin{array}{l}30 \\
3.2 \%\end{array}$ \\
\hline
\end{tabular}


Table 2 (Continued).

\begin{tabular}{|c|c|c|c|c|c|c|}
\hline Factor & $\begin{array}{l}\text { Strong Negative } \\
\text { Impact }\end{array}$ & $\begin{array}{l}\text { Negative } \\
\text { Impact }\end{array}$ & $\begin{array}{l}\text { No } \\
\text { Impact }\end{array}$ & $\begin{array}{l}\text { Positive } \\
\text { Impact }\end{array}$ & $\begin{array}{l}\text { Strong Positive } \\
\text { Impact }\end{array}$ & Total \\
\hline Not sure/ready to some extent & $\begin{array}{l}46 \\
35.1 \%\end{array}$ & $\begin{array}{l}43 \\
41.7 \%\end{array}$ & $\begin{array}{l}68 \\
41.0 \%\end{array}$ & $\begin{array}{l}98 \\
35.4 \%\end{array}$ & $\begin{array}{l}74 \\
27.8 \%\end{array}$ & $\begin{array}{l}329 \\
34.9 \%\end{array}$ \\
\hline Ready/ ready to a great extent & $\begin{array}{l}76 \\
58.0 \%\end{array}$ & $\begin{array}{l}56 \\
54.4 \%\end{array}$ & $\begin{array}{l}91 \\
54.8 \%\end{array}$ & $\begin{array}{l}172 \\
62.1 \%\end{array}$ & $\begin{array}{l}189 \\
71.1 \%\end{array}$ & $\begin{array}{l}584 \\
61.9 \%\end{array}$ \\
\hline \multicolumn{7}{|l|}{ IF7: Fear of getting the disease } \\
\hline & $\begin{array}{l}12 \\
5.9 \% \\
72 \\
35.6 \% \\
118 \\
58.4 \%\end{array}$ & $\begin{array}{l}2 \\
1.7 \% \\
49 \\
41.5 \% \\
67 \\
56.8 \%\end{array}$ & $\begin{array}{l}6 \\
3.9 \% \\
60 \\
38.7 \% \\
89 \\
57.4 \%\end{array}$ & $\begin{array}{l}7 \\
3.3 \% \\
72 \\
34.1 \% \\
132 \\
62.6 \%\end{array}$ & $\begin{array}{l}3 \\
1.2 \% \\
76 \\
29.6 \% \\
178 \\
69.3 \%\end{array}$ & $\begin{array}{l}30 \\
3.2 \% \\
329 \\
34.9 \% \\
584 \\
61.9 \%\end{array}$ \\
\hline \multicolumn{7}{|c|}{ IF8: Fear to transmit the infection to those you care about } \\
\hline & $\begin{array}{l}15 \\
6.0 \% \\
83 \\
32.9 \% \\
154 \\
61.1 \%\end{array}$ & $\begin{array}{l}3 \\
3.1 \% \\
42 \\
43.8 \% \\
51 \\
53.1 \%\end{array}$ & $\begin{array}{l}I \\
0.9 \% \\
4 I \\
38.3 \% \\
65 \\
60.7 \%\end{array}$ & $\begin{array}{l}5 \\
2.9 \% \\
58 \\
33.5 \% \\
110 \\
63.6 \%\end{array}$ & $\begin{array}{l}6 \\
1.9 \% \\
105 \\
33.3 \% \\
204 \\
64.8 \%\end{array}$ & $\begin{array}{l}30 \\
3.2 \% \\
329 \\
34.9 \% \\
584 \\
61.9 \%\end{array}$ \\
\hline
\end{tabular}

however, 4 of them reported that they were ready for physical distancing and 2 were not sure about their level of readiness.

Around 50\% of those who reported that they were not ready at all for physical distancing $(n=17 / 30)$ do recommend further restrictions if there is any increase in the number of infected cases compared to $69.3 \%$ of the ready/ready to a great extent group and $61.4 \%$ of the not sure/ready to some extent group ( $\mathrm{p}$-value $=0.043$ ), as shown in Figure 3 .

The majority of the respondents reported readiness to maintain physical distancing if they resumed work, with a significant difference between the readiness to practice physical distancing group ( $p$-vale $<0.001$ ) while more of the non-ready group reported that they will not be able or not sure if they will be able to maintain physical distancing at work, as shown in Figure 4.

\section{Discussion}

The responses of the statistical analysis revealed that the majority of respondents are females compared to their counterparts. This finding is aligned with previous studies that females represent a large proportion of participants and are more likely to apply safety measures than males. ${ }^{10-12}$ This could be explained as female nature is more likely to take responsibility and be more aware about health and the wellness of themselves and their families. Moreover, there was a more positive attitude towards physical distancing among females and this might be due to the cultural natures of the Omani society that female is considered the caregivers at home who take the responsibility of the family. This is in accordance with the study conducted by $\mathrm{Li}$ and $\mathrm{Xu}, 2020 .{ }^{13}$ In relation to the positive attitude and protective behaviors of the age group 35 to 45 years that appeared in this study, this could be explained as the young population are easily influenced by social media, legacy media (TV, radio), and the COVID-19 published studies and this result supports the study conducted by $\mathrm{Li}$ and $\mathrm{Xu}, 2020$ about family support during COVID $19 .{ }^{13}$

In this study, it was evident that educational level is positively correlated with positive attitudes toward physical distancing and readiness to practice the physical distancing when required. This is in accordance with $\mathrm{Li}$ and $\mathrm{Xu}$, $2020^{13}$ and Bruns et al, $2020^{14}$ that people with a higher level of education show positive attitudes about physical distancing whereas individuals with less educational level show low impact from media in making an effort to apprehend health related information. 


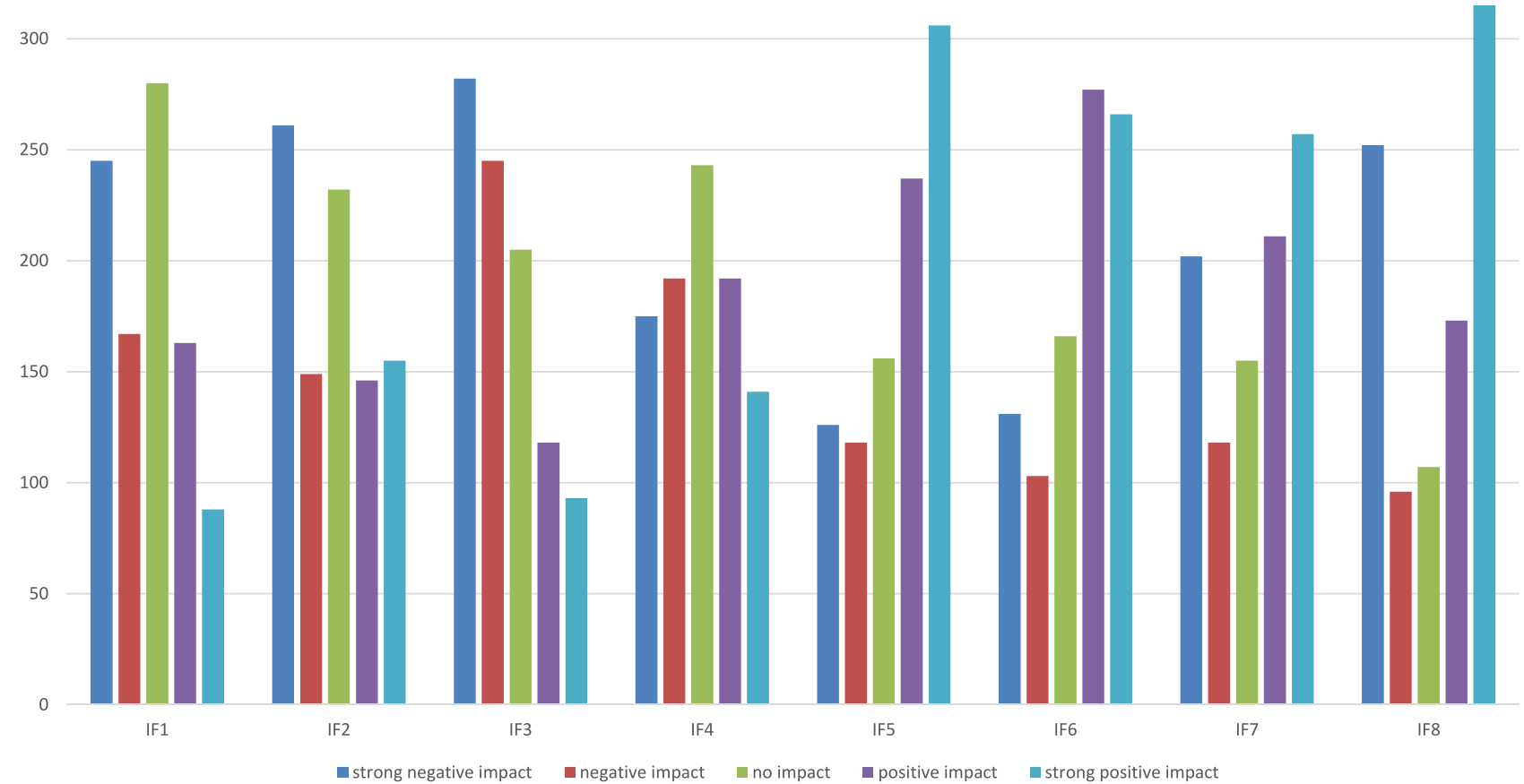

Figure I Showing the impact factors of social distancing.
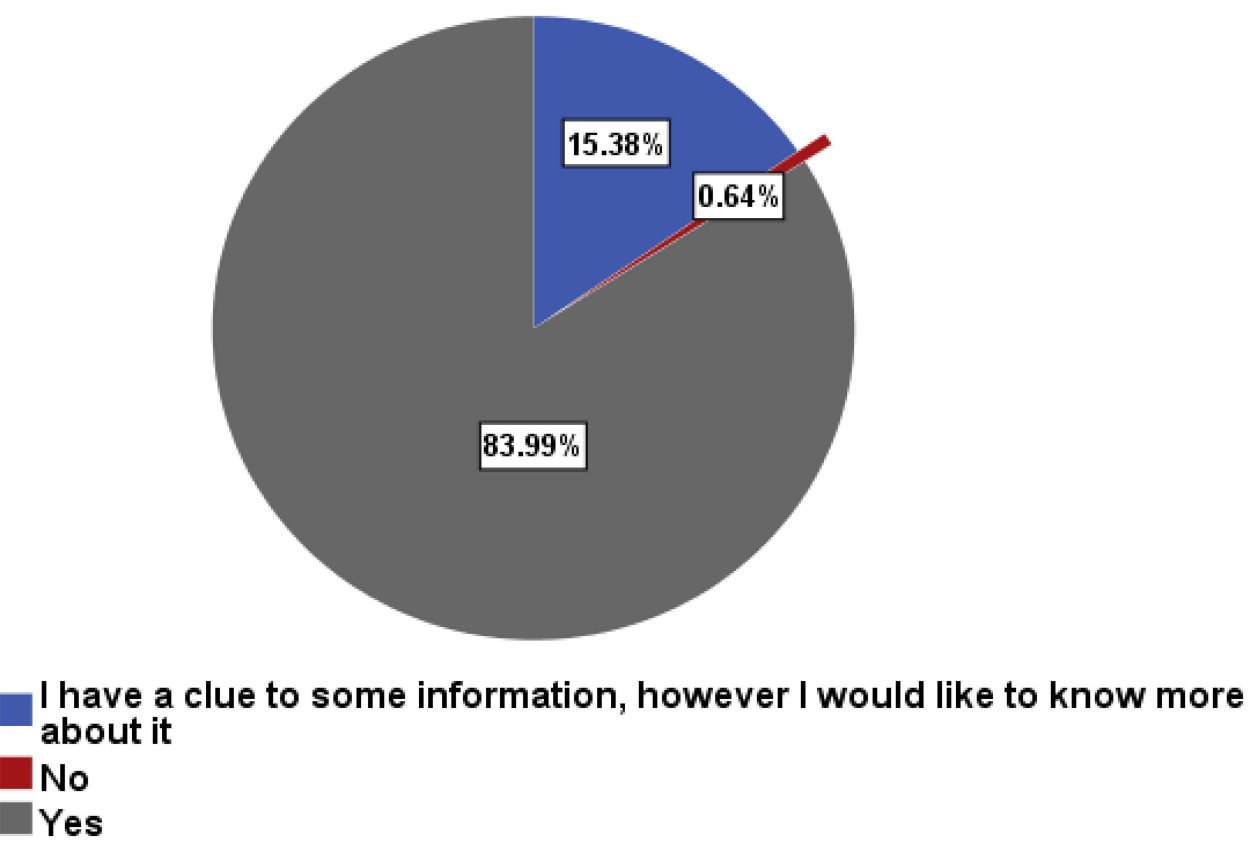

Figure 2 Showing the responses of participants about the meaning of social distancing.

Financial status is considered one of the negative influencers towards physical distancing. In the present study, males had the greater negative impact of financial factors than their counterparts. This could be due to some barriers such as their job and being the bread winner of the family.
This was evident by having more male respondents that reported a negative impact in comparison to female respondents. This result is in accordance with Bezerra Anselmo et al, 2020, ${ }^{10}$ that more males report a financial impact in comparison to females. Additionally, the 


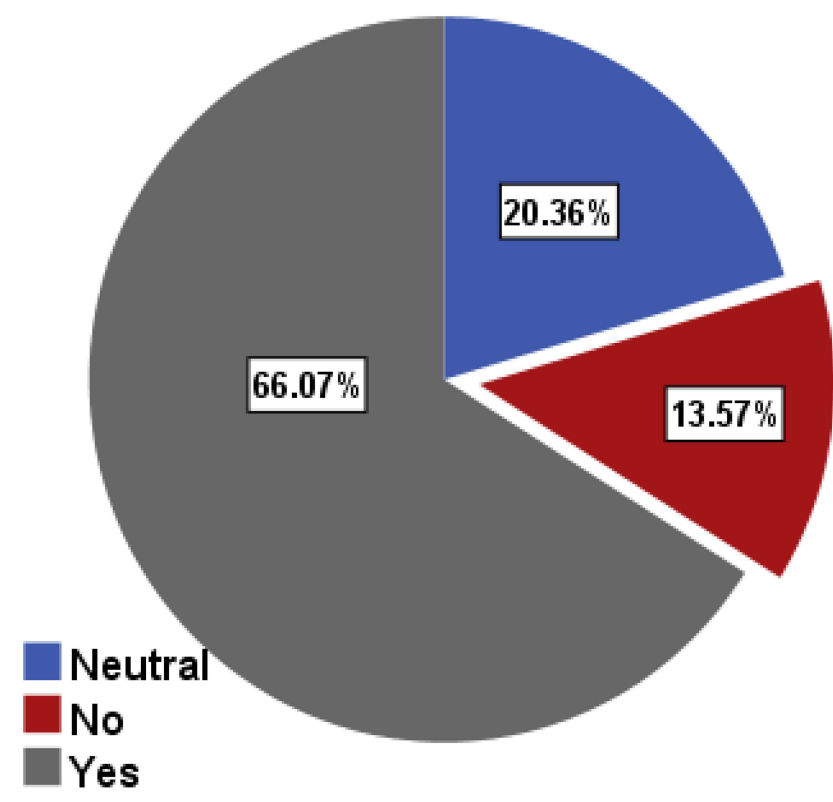

Figure 3 Showing the response of participants to the recommendation of further restrictions in view of the increase in numbers of infected cases to COVID-19.

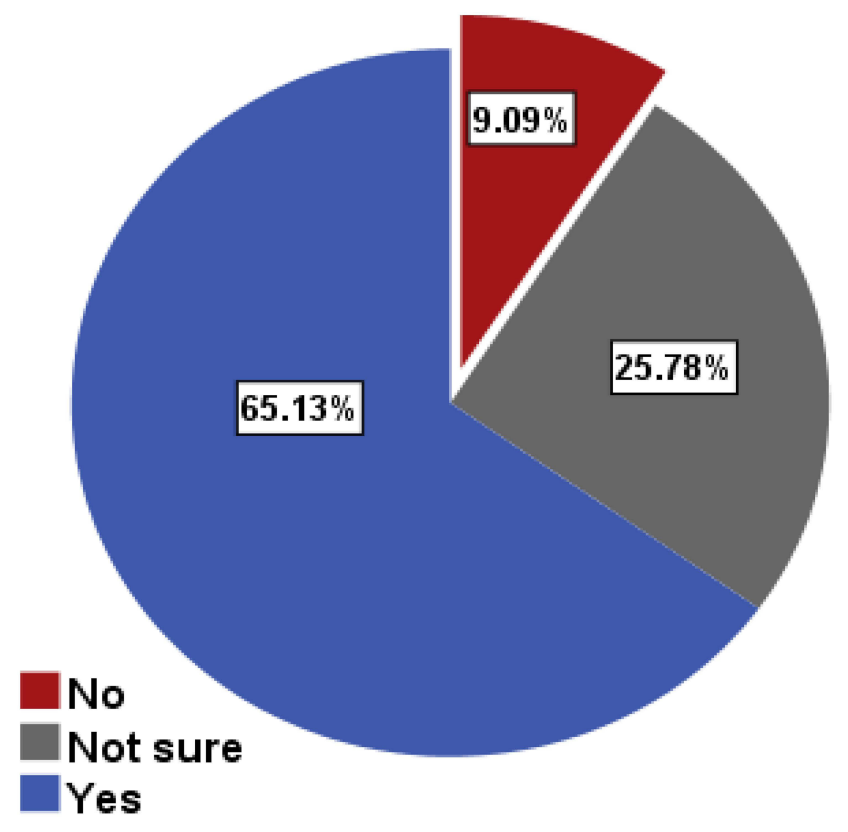

Figure 4 Showing the responses about the ability to maintain social distancing once they resume work and activities normally.

majority of respondents were from middle class families who had less ability to decide about staying at home which limits the efforts to control the spreading of an infection. This may highlight the importance of creating a policy of income-mitigation for individuals who cannot stay at home during a pandemic crisis to mitigate the financial burden.
By late July 2020 people may have been experiencing fatigue from extended indoor quarantining and started returning to their normal behavior which could explain further the results of this study that a majority of people experienced a negative effect of physical distancing as there was uncertainty of the indoor isolation period. This effect raises a concern of self-isolation, how it can be continued and balanced with the effect of financial burden on the community and countries. Therefore, to have a better control and change the behavior of the public, it is recommended to use public campaigns, social media, and national news to highlight the compassionate attitude of physical distancing. ${ }^{15,16}$

Our results showed that physical distancing negatively impacted the practice of religious activities and worship such as going for prayer in the mosques, Eid celebration and Eid prayer, and going for Haj (Haj is a ritual journey to Makkah and considered the fifth essential pillar in Islam). This ritual is conducted on the 12th month of the lunar Islamic calendar, namely, "Dhul Hijjah"17, and going for Umrah (religious practice in Islam that requires travel to KSA Makah city). ${ }^{17}$ These religious practices were strictly controlled during the pandemic and people were not allowed to practice their prayers as groups in mosques. In this study, it was found that males have a strong negative impact of physical distancing to practicing their religious activities. This is usual when we understand the nature of the culture and religion that men are mandated for some religious practices, for example, Friday prayer whereas females are not mandated to attend the Friday prayer in the mosque and can perform the prayer at home. Moreover, Haj, which is required once during a lifetime, happened once every year and people get selected through the ministry of religious affairs and selection priority is for those who have never been, the elderly, or individuals with chronic illnesses. There has been no study conducted yet to explore the impact of COVID-19 on religious practices and this could be a unique consideration for Islamic society.

In this study, it was obvious that culture and norms could have a negative impact towards maintaining the physical distancing during a pandemic. Examples of a country's culture and norms are; family gathering and celebrations, Eid gathering, visiting sick people either within the family or relatives, and handshaking as part of greeting. By having such practices, the public have a negative impact to comply with the order of physical distancing, this could negatively affect the public practice 
of physical distancing when required and add a further burden on health sectors at any stage when physical distancing is required. This negative impact could be due to stigmatization of the community toward infected and cured individuals, or difficulties of maintaining the safety measures such as avowing family gathering, handshaking, kissing, or social visits between families. These findings of negative impact support the other studies of infectious disease pandemics and stigmatization which can negatively affect populations of people who seek medical care. $^{14}$

Another explanation of this negative impact could be due to the nature of extended families in Oman. The majority of families are extended (grandmother, grandfather, parents, children, and grandchildren) usually share the same house or live by each other. Therefore, when the young individuals of the family attend their work or college, they may not be able to practice the physical distancing when returning home due to limits of rooms per individuals at home. This could be a unique factor as culture and norms are strictly followed in Oman especially by the elderly. However, what can be maintained by physical distancing in Western countries could not be applied in Oman due to the cultural effect as the role of culture and norms derive the human behaviors. This requires the public health authorities to seek alternative strategies of physical distancing during pandemics such as continuous education toward infection prevention through media and respected individuals within the community like famous individuals, football players or clergy.

In this study, it was evident that participants who were ready to practice physical distancing had more positive impact towards family and friend's support and this could be due to the presence of extended families within the country. This study extends the previous literatures that families developed intimacy and empathy among family members during pandemics. ${ }^{18}$ Moreover, as shown in the results of this study, females exhibit a greater positive attitude of physical distancing than males did. This is in support of $\mathrm{Li}$ and $\mathrm{Xu}, 2020 .^{13}$ This could be explained as the female role within the culture is more supportive, showing a caring attitude toward their families and applying health measures to protect their families.

Moreover, this study highlights a unique finding about public acceptance of further restrictions when there is a rise of infected cases and this is considered as a healthy vision from the public in controlling the spread of infection. However, the group who supported further restrictions are those who reported non-readiness to practice the physical distancing behavior. Therefore, the practice of physical distancing could be emphasized more by family medicine (primary healthcare in Oman). The emphasis of physical distancing that could be done by the family means medicine could be practiced vitually either through telemedicine or through the use of social media $^{19}$

The World Health Organization (WHO) published several guidelines on how to control COVID-19 by reducing the risk of the virus transmission and preventing associated illnesses and death. ${ }^{20}$ The main concepts of these public health measures are to break the chains of transmission by strategy, including (1) identification, isolation, testing, and clinical care for all cases, (2) tracing and quarantine of contacts, and (3) encouraging physical distancing of at least 1 meter combined with frequent hand hygiene and respiratory etiquette. These three components should be central to every national COVID-19 response.

In Oman, the Supreme COVID-19 Committee, decided to suspend all domestic and international flights to and from the Sultanate's airports with effect from Sunday, March 29th, 2020. The committee started to arrange the return of citizens, particularly students, to their home countries and to provide institutional or home quarantine to ensure the non-proliferation of the virus. Beside the quarantine, the committee issued several decisions enforcing social distancing, like closing all mosques and worship areas, suspending all gatherings, activities and conferences, closing all tourist sites and prohibiting assembling in public areas, closing all shops in all commercial complexes, malls and shopping outlets, closing traditional markets, prohibiting serving food at restaurants, cafes and cafeterias, and closing all sport clubs.

Several studies investigated people who underwent home quarantine and the effect on their mental health and psychological wellbeing. Symptoms of stress related to quarantine including low mood, irritability, insomnia, anger, and emotional exhaustion. A survey was conducted on hospital staff (338) placed on quarantine during the SARS epidemic which showed that the act of quarantine was the most related factor to the development of acute stress disorder. ${ }^{21}$ Other associated factors include stigmatization and uncertainty due to inadequate information. A recent publication shows that prolonged home stay may lead to reduced level of physical activity and affect general health status. ${ }^{22}$ Finally, these changes of lifestyles may lead to increased sedentary and inactive behaviors, 
such as prolonged sitting time, lying down for passive activities, with a subsequent impact on physical wellbeing.

\section{Limitation}

Although the sample of this study exceeded the calculated size and with a power of $80 \%$, this sample may not represent all strata of the population as the elderly population in this study does not resemble the proportion within the country. This is due to unstratified sampling design. Moreover, the citizens sampled in this study are not representative and results may be underestimated which could be due to the diverse language used by citizens or due to the inability of the data collectors to reach this group of the population. Moreover, the study was conducted in the middle of the COVID-19 pandemic era and people could be more relaxed in comparison to the start of the pandemic. Therefore, we recommend future researchers to conduct similar studies and consider the stratification of the sample to be more representative and include all age categories and citizens.

\section{Recommendation}

Several key recommendations to be addressed from the results of this study, it is obvious that culture and norms drive human behavior even during a pandemic. Therefore, health authorities and governmental legislation should apply measures gradually to derive human behavior changes especially in a strong community for the measures to be accepted in the community. This could be done by launching campaigns that can raise the community's awareness and actively engage them in learning and searching for precautionary measures related to COVID19. ${ }^{11}$ Leaders of faith-based organizations and who are considered as role models for the community need to emphasise the importance of physical distancing, hand hygiene and avoiding unnecessary mass gatherings. ${ }^{19}$ Moreover, each country should be well prepared for unexpected future pandemics to avoid repeating the same errors. This could be done by putting some proportion of a country's income into a fund put aside for any emergency. $^{23}$

As was obvious from the analysis, a smaller proportion of elderly groups and residents responded to the survey. Thus, the authorities/National Health Committee ought to present/ introduce the approach to text people with information about COVID-19 in numerous languages to spread the awareness to the majority of the population. This measure will help to enhance the level of knowledge of different age groups, who speak different languages and the population of the countryside with poor internet connection. ${ }^{11}$

Continuous educational programs could be done regardless of the pandemic to enhance and educate the community on the preventive measures that will help reduce the stress the population encounter during a pandemic. The gained knowledge will help to build the public's confidence and will reduce stress and anxiety. ${ }^{18}$ Regarding the financial impact, it is important to create a policy of income-mitigation for individuals who cannot stay at home during a pandemic crisis as a way of reducing the financial burden.

One of the important recommendations is to apply human behavioral changes (reflective and automatic processes driving behavior) within the society as a predictor to adopt preventative health behaviors such as the use of non-stigmatizing behavior and non-blaming culture within the community to enhance the stigmatized individuals to seek medical advice when the symptoms appear. $^{15}$

\section{Conclusion}

This cross-sectional study that was conducted during the first wave of the COVID-19 pandemic highlighted the readiness of a population to practice physical distancing, their knowledge of physical distancing, and the impact of physical distancing on different life factors. Two unique findings of this study that added knowledge to the current literature on public practice that are religious practices and culture and norms within the society. Religious practices mainly negatively affected the male gender. Moreover, the study supports the hypothesis that there are certain values in Oman that affect the practice of physical distancing in a pandemic event. Therefore, culture and norms derive the human behavior within communities and may affect the safety measures during an outbreak or pandemic. Moreover, readiness to practice physical distancing was relatively high for the population in the capital city (64\%). Even with the availability of vaccinations, campaigns on public health should be the national practice to continue emphasizing compassionate attitudes towards physical distancing.

\section{Disclosure}

The authors report no conflicts of interest in this work. 


\section{References}

1. da Costa VG, Moreli ML, Saivish MV. The emergence of SARS, MERS and novel SARS-2 coronaviruses in the 21st century. Arch Virol. 2020;165(7):1517-1526. doi:10.1007/s00705-020-04628-0

2. Johansen MD, Irving A, Montagutelli X, et al. Animal and translational models of SARS-CoV-2 infection and COVID-19. Mucosal Immunol. 2020;13(6):877-891. doi:10.1038/s41385-020-00340-Z

3. Lai -C-C, Shih T-P, Ko W-C, et al. Severe acute respiratory syndrome coronavirus 2 (SARS-CoV-2) and coronavirus disease-2019 (COVID-19): the epidemic and the challenges. Int $J$ Antimicrob Agents. 2020;55(3):105924. doi:10.1016/j.ijantimicag.2020.105924

4. Al Maskari Z, Al Blushi A, Khamis F, et al. Characteristics of healthcare workers infected with COVID-19: a cross-sectional observational study. Int $J$ Infect Dis. 2021;102:32-36. doi:10.1016/j. ijid.2020.10.009

5. Khamis F, Al-Zakwani I, Al Naamani H, et al. Clinical characteristics and outcomes of the first 63 adult patients hospitalized with COVID-19: an experience from Oman. $J$ Infect Public Health. 2020;13(7):906-913. doi:10.1016/j.jiph.2020.06.002

6. Dhand R, Li J. Coughs and sneezes: their role in transmission of respiratory viral infections, including SARS-CoV-2. Am J Respir Crit Care Med. 2020;202(5):651-659. doi:10.1164/rccm.202004-1263PP

7. Oran DP, Topol EJ. Prevalence of asymptomatic SARS-CoV-2 infection. Ann Intern Med. 2020;173(5):362-367. doi:10.7326/M203012

8. Gao Z, Xu Y, Sun C, et al. A systematic review of asymptomatic infections with COVID-19. J Microbiol Immunol Infect. 2020. doi:10.1016/j.jmii.2020.05.001

9. Humphreys J. The importance of wearing masks in curtailing the COVID-19 pandemic. J Family Med Prim Care. 2020;9 (6):2606-2607. doi:10.4103/jfmpc.jfmpc_578_20

10. Bezerra ACV, Silva CE, Soares FR, Silva JA. Factors associated with people's behavior in social isolation during the COVID-19 pandemic. Cien Saude Colet. 2020;25(suppl 1):2411-2421.

11. Aldarhami A, Bazaid AS, Althomali OW, et al. Public perceptions and commitment to social distancing "staying-at-home" during COVID-19 pandemic: a national survey in Saudi Arabia. Int J Gen Med. 2020;13:677-686. doi:10.2147/JJGM.S269716

12. Meza D. In a pandemic are we more religious? Traditional practices of catholics and the COVID-19 in Southwestern Colombia. Int J Lat Am Relig. 2020;4(2):218-234. doi:10.1007/s41603-020-00108-0
13. Li S, Xu Q. Family support as a protective factor for attitudes toward social distancing and in preserving positive mental health during the COVID-19 pandemic. J Health Psychol. 2020;1359105320971697. doi:10.1177/1359105320971697

14. Bruns DP, Kraguljac NV, Bruns TR. COVID-19: facts, cultural considerations, and risk of stigmatization. J Transcult Nurs. 2020;31 (4):326-332. doi:10.1177/1043659620917724

15. Coroiu A, Moran C, Campbell T, et al. Barriers and facilitators of adherence to social distancing recommendations during COVID-19 among a large international sample of adults. PLoS One. 2020;15 (10):e0239795. doi:10.1371/journal.pone.0239795

16. Bellato A. Psychological factors underlying adherence to COVID-19 regulations: a commentary on how to promote compliance through mass media and limit the risk of a second wave. Soc Sci Humanit Open. 2020;2(1):100062. doi:10.1016/j.ssaho.2020.100062

17. Khan EA, Shambour MKY. An analytical study of mobile applications for Hajj and Umrah services. Appl Comput Inform. 2018;14 (1):37-47. doi:10.1016/j.aci.2017.05.004

18. Yoosefi Lebni J, Abbas J, Moradi F, et al. How the COVID-19 pandemic effected economic, social, political, and cultural factors: a lesson from Iran. Int J Soc Psychiatry. 2021;67(3):298-300.

19. Sahu K, Kumar R. Preventive and treatment strategies of COVID-19: from community to clinical trials. J Family Med Prim Care. 2020;9 (5):2149-2157. doi:10.4103/jfmpc.jfmpc_728_20

20. World Health Organization. Considerations for Quarantine of Contacts of COVID-19 Cases: Interim Guidance. A.N.W.-n.I.Q; 2020.

21. Bai Y, Lin CC, Lin CY, Chen JY, Chue CM, Chou P. Survey of stress reactions among health care workers involved with the SARS outbreak. Psychiatr Serv. 2004;55(9):1055-1057. doi:10.1176/appi. ps.55.9.1055

22. Brooks SK, Webster RK, Smith LE, et al. The psychological impact of quarantine and how to reduce it: rapid review of the evidence. Lancet. 2020;395(10227):912-920. doi:10.1016/S0140-6736(20) 30460-8

23. Calisher CH. Good news or bad news? The coronavirus pandemic has sickened and killed only a relatively few people but has affected us all. Croat Med J. 2020;61(3):296-299. doi:10.3325/cmj.20 20.61.296
International Journal of General Medicine

\section{Publish your work in this journal}

The International Journal of General Medicine is an international, peer-reviewed open-access journal that focuses on general and internal medicine, pathogenesis, epidemiology, diagnosis, monitoring and treatment protocols. The journal is characterized by the rapid reporting of reviews, original research and clinical studies across all disease areas. The manuscript management system is completely online and includes a very quick and fair peer-review system, which is all easy to use. Visit http://www.dovepress.com/ testimonials.php to read real quotes from published authors. 